\title{
A Study to evaluate the factors influencing on Family planning practices among urban married women in Bangalore.
}

\author{
Dr.HajiraSaba.I $I^{1}$. Dr.K.Kishore ${ }^{2}$, \\ I(Assistant Professor, Department of Community Medicine, Vydehi Institute of Medical Sciences and Research \\ Center, Bangalore-560066.INDIA). \\ ${ }_{2}^{2}$ (Professor \&H.O.D, Department of Community Medicine, Dr.B.R.Ambedkar Medical College, Bangalore- \\ .560045.INDIA)
}

\begin{abstract}
:
Introduction: Family planning is one of the fundamental pillars of safe motherhood and a reproductive right. The practice of family planning is influenced by socio-demographic factors, hence its variation between regions of the world and countries. It is pertinent to reposition family planning to accelerate the reduction of maternal and neonatal mortality in less developed countries.Aim: To evaluate the factors influencing the family planning practices among married women. Study Design: It is a community based cross-sectional study. Study Area: Urban area of Dr. B.R. Ambedkar Medical College. Study Population: Married women in the reproductive age group of 15-45 years. Materials And Methods: 300 married women in the urban area of Dr. B.R. Ambedkar Medical College were interviewed and examined using a pre-tested and semi-structured questionnaire after obtaining informed oral consent. Married women were interviewed with respect to the socio economic status, educational status, age at marriage, married life, total number of children, usage of contraceptive methods, reasons for non usage.Results:35.35\% were aged between 25-29 years of age. 59\% were Hindus, 35.3\%were Muslims and $5.7 \%$ were Christians. $71.7 \%$ were belonging to Nuclear families. $51.3 \%$ had secondary level of education. $84 \%$ of women were housewives and were belonging to Class III (lower middle) socio-economic status. $36.66 \%$ had two living children Conclusion: $58.6 \%$ were currently using contraception. $71.59 \%$ had undergone Tubectomy and none were found who had adopted Vasectomy.. Reasons for not using contraception for $56.48 \%$ was desire for more Children, $20.16 \%$ as need not felt, $10.48 \%$ as against religion and misconception about contraception and $0.80 \%$ as mother in law opposition, lack of information and fear of side effects. $92.2 \%$ had negative opinion towards male sterilization and $57.4 \%$ gave reason for negative opinion as weakness will develop in males following male sterilization.
\end{abstract}

Key words: Family Planning, Factors, Married women, urban area.

\section{Introduction}

WHO defined Family planning as "a way of thinking and living that is adopted voluntarily, upon the basis of knowledge, attitudes and responsible decisions by individuals and couples, in order to promote the health and welfare of the family group and thus contribute effectively to the social development of the country" [1]. "Women and men in many countries still lack adequate access to contraceptives, unless they are given the option of controlling their fertility, several environmental and health problems loom in the coming century throughout large parts of the world" ${ }^{[2]}$.More than 100 million women in developing countries or about $17 \%$ of all married women would prefer to avoid a pregnancy but are not using any form of family planning ${ }^{[3]}$. "It is estimated that 1,00,000 maternal deaths could be avoided each year if all women who said they want no more children were able to stop child bearing" and "Achieving adequate birth spacing (more than two years apart) could reduce child death by up to a third in some countries" ${ }^{\text {[4] }} 15.8 \%$ women are not using any method of contraception but would still wait for 2 years before having a child. These women are described as having an "unmet need for family planning" ${ }^{[5]}$.Despite heavy measures taken by various governments in developing countries, fertility is still on the rise. For example, men and women in these countries tend to want large families with husbands desiring more children than their wives ${ }^{[6]}$. In a diverse and relatively young independent country such as India, infrastructure, implementation, education and public opposition proved to be barriers for initial family planning attempts. Since fertility in India is primarily marital, the aim of this study is to look at some factors that may affect different methods of contraception among married women at the different level ${ }^{[7]}$. The reasons for adopting sterilization, on use and discontinuation of contraceptive methods, by women, need to be evaluated for, better acceptance of the contraceptives, for reassessing the changes required in promotional strategies of the spacing methods and further developing and/or modifying the appropriate promotional strategies of the spacing methods.The present study was therefore undertaken to assess the desire for contraception among married women in urban community and the barriers that restrict them from practicing it. 


\section{Aim And Objective}

1. To evaluate the factors influencing the family planning practices among married women in the age group of $15-45$ years.

\subsection{Type of the study 1.2 Area of the study 1.3 Study Population}

\subsection{Inclusion Criteria:}

-Women who are married, age of 15-45 years and presumed to be sexually active.

-Pregnant and post partum amenorrhoeic women are also included.

1.5 Exclusion Criteria Those who are not willing to participate.

- Unmarried women.

1.6 Study period December 2010-December 2011.

1.7 Sampling Design Systematic Random Sampling.

1.8 Sample Size_. The sample size was 300, calculated by taking the prevalence rate of contraceptive use (56.3\%) at $5 \%$ significance level and $10 \%$ error.

Urban area of Dr.B.R.Ambedkar medical college covers a population of 79,667, of which married couple population is 11,533. Married women were selected based on systematic random sampling method.300 Married women aged around 15-45years were visited in the areas and were interviewed by obtaining oral informed consent.

\subsection{Data collection}

After conducting a pilot study in 50 subjects, necessary modifications were made in the proforma and the present study was undertaken. The data was collected by interviewing the woman using a predesigned and pretested proforma in their own local language, during home to home visit. Information was collected regarding her age, education, occupation, religion, income and also about her marital history like her age at the time of marriage, duration of married life, her present parity status, if she was pregnant or post partum amenorrhoeic and also regarding the use of contraception. The reasons for non use of contraceptives were meticulously enquired after taking the women into complete confidence. At the end of the questionnaire, any misconceptions or queries regarding were clarified and the respondent were thanked for extending her co-operation.

\subsection{Data analysis}

Chi-square test was used to test the association between the factors influencing and family planning practices. The data analysis was done using statistical software Mini-tab and SSP.

\section{Results}

106(35.3\%) were aged between 25-29 years of age. 177(59\%) were Hindus, 106(35.3\%) were Muslims and $17(5.7 \%)$ were Christians in the study.215 (71.7\%) were belonging to Nuclear families. $153(51 \%)$ had secondary level of education, $46(15.3 \%)$ were illiterates, 38(12.7\%) were Degree holders.154 (51.3\%) of husbands had Secondary level of education.252(84\%) of women were housewives and were belonging to Class III (lower middle) socio-economic status according to Modified Kuppaswamy's classification. Age at marriage in the study group 192(64\%) was between 18-23years of age ,177(59\%) duration of married life was $\leq 10$ years. $110(36.66 \%)$ had two number of living children. In the study group, $145(50.34 \%)$ the age at first pregnancy is between 19-23years. Those who preferred son, $46(63.88 \%)$ gave reason as son can be a future source of income. $176(58.6 \%)$ were current users of contraception. 54(30.68\%) of current users were in the age group of 2529years.126 (71.59\%) had undergone Tubectomy and none were found who had adopted Vasectomy as a contraceptive method in the study population.81(46.02\%) of current users had Secondary level of education and $180(60 \%)$ who had children were belonging to Class III socio-economic status and $82(46.6 \%)$ of current users had two children.156(88.7\%) women used contraception to limit their family size and 122(69.4\%) used contraception after birth of first child. 
Fig-1 Distribution of the study population according to the desired family size.

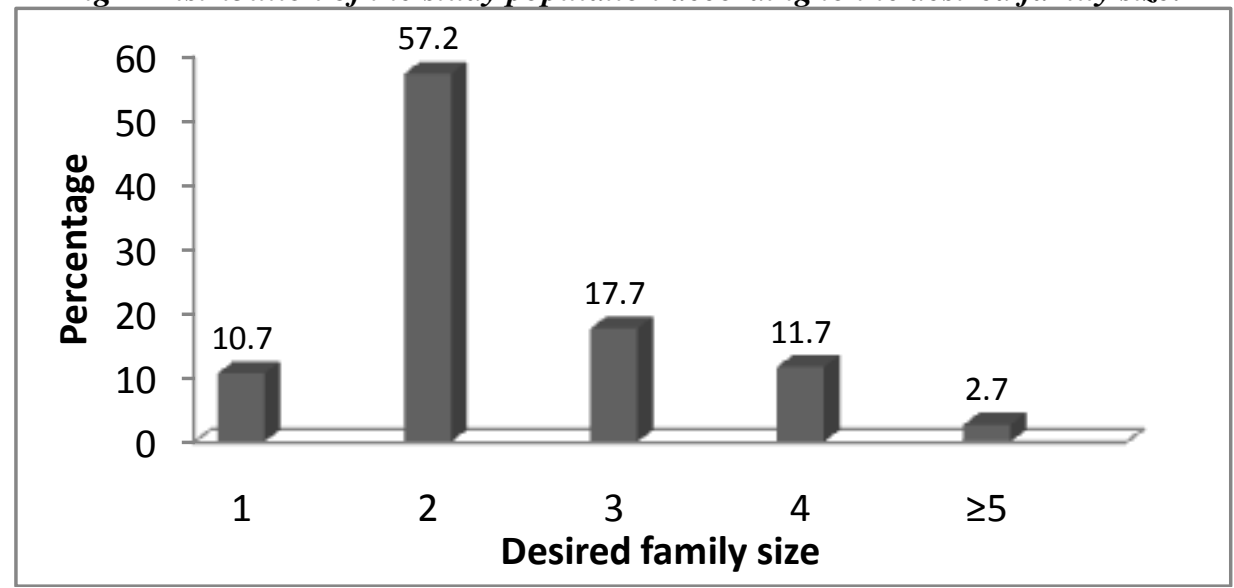

Reasons for not using contraception for 70(56.5\%) was desire for more Children, 25(20.2\%) as need not felt, $13(10.5 \%)$ as against religion and misconception about contraception and $1(0.80 \%)$ as mother in law opposition, lack of information and fear of side effects.

Fig-2 Distribution of the study population according to the Reasons for not using contraception.

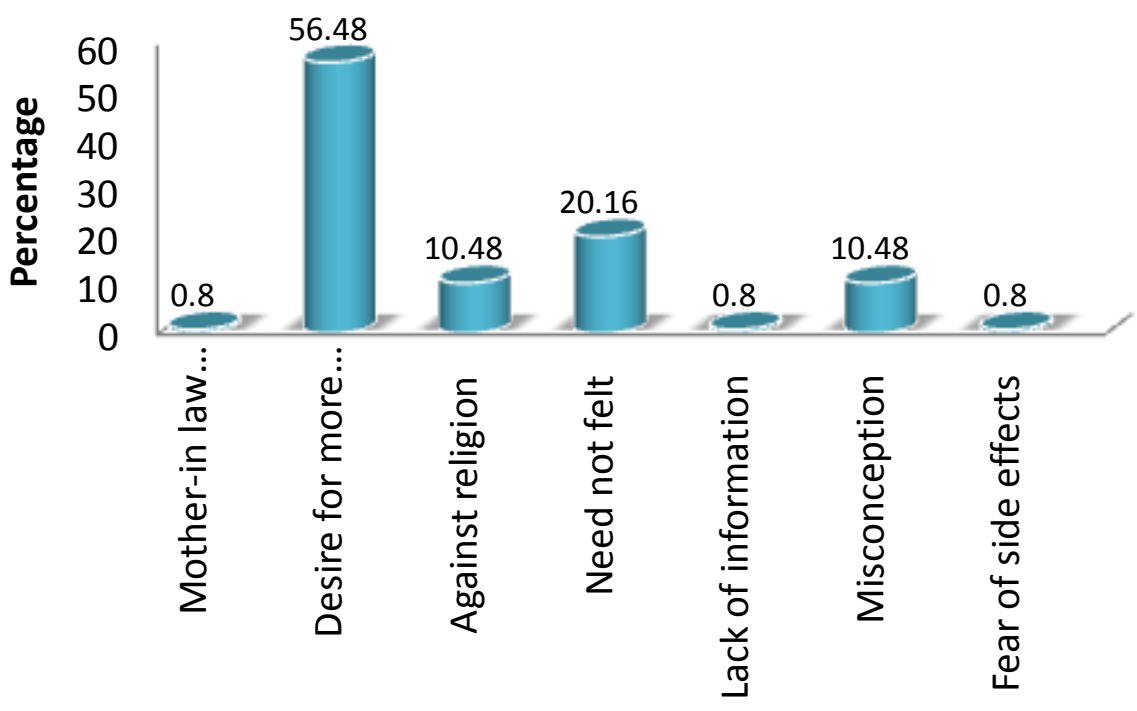

Fig-3 Distribution of the study population according to the Reasons for Son preference.

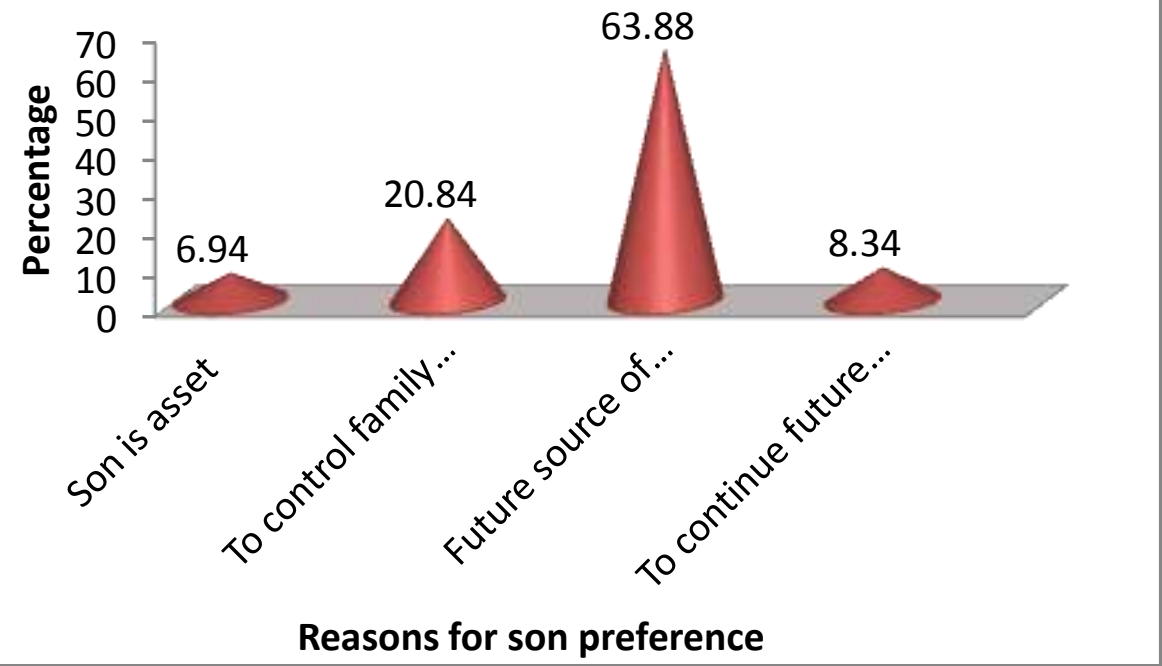


Fig-4 Distribution of the study population according to the Type of contraception used.

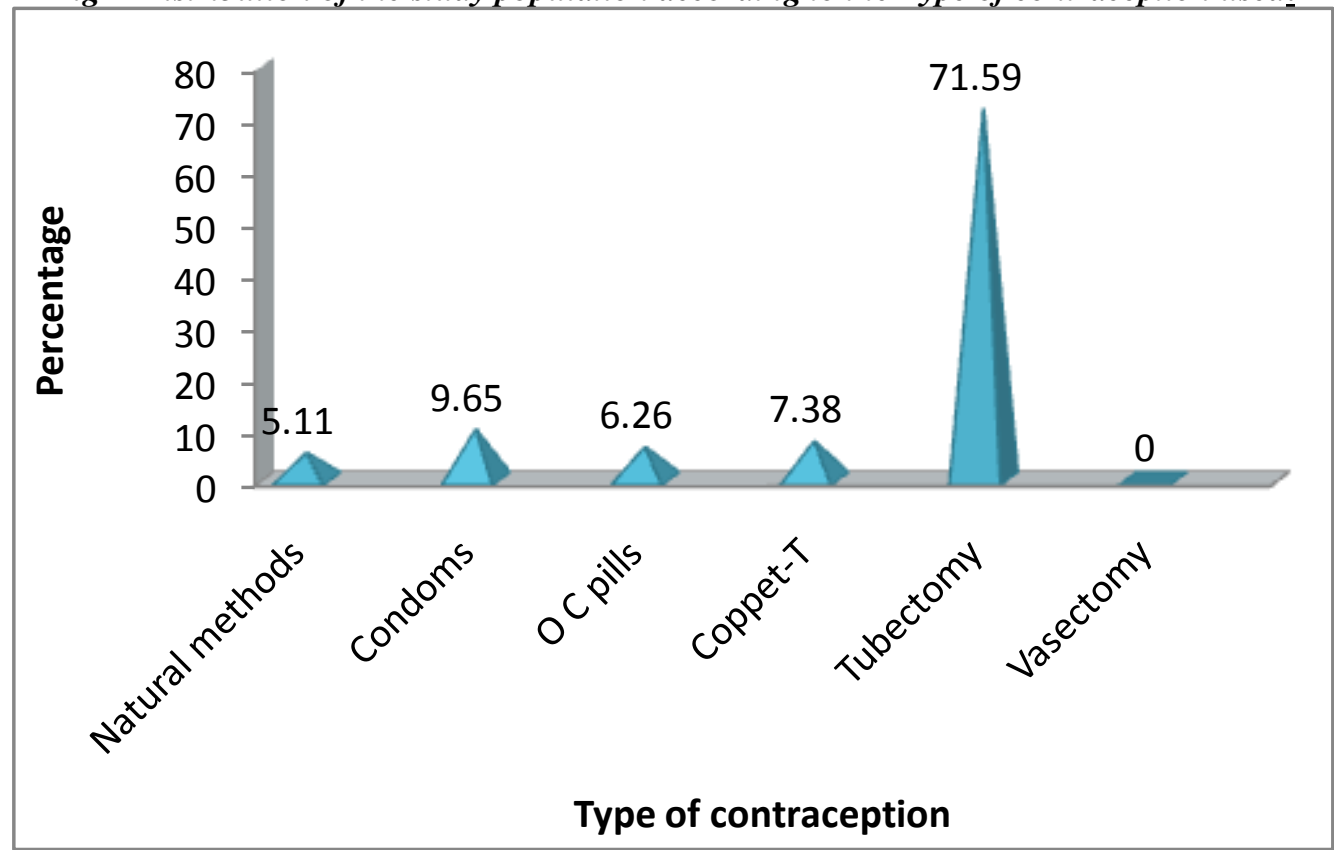

Fig-5 Distribution of the current users of contraception according the Time of usage.

TABLE-1 Distribution of the study population according to the reasons for negative opinion towards male sterilization.

\begin{tabular}{|l|l|l|}
\hline Reasons for negative opinion & No of Respondents & Percentage (\%) \\
\hline Fear of side effects & 6.0 & 4.6 \\
\hline Weakness in males & 74 & 57.4 \\
\hline Males should not be operated & 49 & 38.0 \\
\hline Total & 129 & 100 \\
\hline
\end{tabular}

$129(92.2 \%)$ had negative opinion towards male sterilization and 74(57.4\%) gave reason for negative opinion as weakness will develop in males following male sterilization.280 (93.4\%) of husbands of study population had agreed for contraception and 20(6.6\%) had disagreed.284 (94.4\%) of husbands wanted same number of children as wife and $15(5 \%)$ wanted more number of children than wife. 


\begin{tabular}{|c|c|c|}
\hline $\begin{array}{l}\text { Age in yrs } \\
15-19 \\
20-24 \\
25-29 \\
30-34 \\
35-39 \\
40-45\end{array}$ & Type of contraception & $\begin{array}{c}\text { P-value } \\
<0.001\end{array}$ \\
\hline $\begin{array}{l}\text { Religion } \\
\text { Hindu } \\
\text { Muslim } \\
\text { Christian } \\
\text { Others }\end{array}$ & Total number of living children & $<0.05$ \\
\hline $\begin{array}{l}\text { Type of contraception } \\
\text { Natural } \\
\text { Condoms } \\
\text { Copper-T } \\
\text { OC-Pills } \\
\text { Tubectomy }\end{array}$ & Religion & $<0.01$ \\
\hline $\begin{array}{l}\text { Educational status } \\
\text { Illiterate } \\
\text { Primary } \\
\text { Secondary } \\
\text { PUC } \\
\text { Degree } \\
\end{array}$ & Type of contraception & $<0.001$ \\
\hline $\begin{array}{l}\text { Socio economic status } \\
\text { CLASS I } \\
\text { CLASS II } \\
\text { CLASS III } \\
\text { CLASS IV } \\
\text { CLASS V } \\
\end{array}$ & Total number of living children & $<0.05$ \\
\hline $\begin{array}{l}\text { Total number of living children } \\
0 \\
1 \\
2 \\
3 \\
4 \\
>5\end{array}$ & Type of contraception & $<0.001$ \\
\hline
\end{tabular}

\section{Discussion}

Contraceptives provide a safe and effective way to regulate fertility and preserve health. In addition to their effectiveness in preventing pregnancy, some contraceptives also have substantial non-contraceptive health benefits.

The use of modern contraceptive methods, including voluntary sterilization, to avoid unplanned childbearing has increased rapidly over the past 30 years, especially in countries with strong family planning programmes. Almost all of this increase reflects greater use by women rather than by their partners.

Yet worldwide, an estimated 228 million women or roughly about one in six women of reproductive age are in need of effective contraceptive methods ${ }^{[8]}$.

Substantial proportions of women in every country-more than 50\% in some say their last birth was unwanted or mistimed. More than 50 million of the 190 million pregnancies worldwide each year end in abortions; many of these procedures are clandestine and performed under unsafe conditions ${ }^{[8]}$.

Birth rates would fall heavily if all the women who did not want more children actually succeeded in stopping their child bearing: the number of births would be cut by about a quarter in Africa and about a third in Asia and Latin America. There is clearly a great unfulfilled need or unmet need for family planning, and India alone has around 40 million married women having unmet needs for family planning ${ }^{[9]}$.

If all women who say that they want to space or limit births were to use family planning, the contraceptive prevalence rate of currently married couples would increase drastically and this in turn would have an impact on the total fertility rate ${ }^{[9]}$.

With increase in literacy level, the prevalence of spacers in the unmet need group have significantly increased and that of limiter decreased. The prevalence of spacers significantly decreased and limiter increased with the increase in the number of living children. The major reason for unmet need was opposition from husband /family and community $(32 \%)^{[10]}$.

A community based cross sectional study was carried out in married reproductive age group women in Urban Health Centre field practice area of Govt Medical College, Aurangabad. The study aimed to find out extent and socio-demographic correlates of unmet need for family planning. It was found that $20.54 \%$ of study subjects had unmet need for contraception, $3.61 \%$ for spacing births and $16.93 \%$ for limiting births. The main 
reasons for unmet need were, little perceived risk of pregnancy due to pre-menopausal age (32.47\%), lactation $(31.16 \%)$ and ignorance $(12.32 \%)^{[11]}$.

A study conducted in Belgaum and Gulbarga districts of Karnataka in the year 1990 showed that the practice of family planning was limited to sterilization methods, and that women accepted early sterilization, but usually after having three living children. The majority of the non-users had short open birth intervals (less than two years). The main reason for not using contraceptives was the desire for more children and $18 \%$ specifically stated that they wanted male children ${ }^{12}$.

In study conducted in the district of Dakshina Kannada it was found that, seventy one percent of women with three or more children were acceptors of permanent methods of contraception. Couple protection rate was $28 \%$. Non-acceptors of family planning methods were higher among the Muslims. Education level of the respondents was not influencing the acceptance of family planning methods ${ }^{[13]}$.

Bulatao\& Lee have viewed fertility as being determined by the supply of children, the demand for children \& the material and non material costs of fertility regulation. The supply of children is determined by natural fertility and the rate of survival of children. The former is considered to be a product of post partum abstinence, spontaneous intrauterine mortality, age of permanent fertility, age at first marriage, \& rates of marital disruption. The survival rates of children, on the other hand, depend on factors such as "mother's age \& parity; both parents socio-economic status, including education and income; the adequacy of delivering water; the availability of health care and the control of disease; nutrition; and a host of other factors" ${ }^{\text {"[14] }}$.

P.S.Nair, Griffith Feeney et al examines seven factors that might influence a women's use of privatesector services: age; urban/rural residence, education, religion, membership in a scheduled tribe, electronic media exposure, and geographic region. Urban residence and higher levels of education emerge as the variables most closely with use of private-sectors of family planning ${ }^{[15]}$.

Finally, all the studies conducted in India and abroad show that unmet need for limiting increases linearly with parity and increases in a U-shaped pattern with age. Unmet need varies inversely with education. Unmet need is attributed to weakly held fertility preferences, perception of low risk of conception, lack of contraceptive information, unacceptability of contraception, opposition from husband to contraceptive use or perceived costs, fear of side effects and inadequate family planning services.

Illiterate women more often accepted sterilization (25\%) than the literate women (15\%).This is because illiterate women had more children. About $30 \%$ of illiterate women had 3 or more children as opposed to $16.2 \%$ of literate women. However, literacy status did not influence the choice of any specific spacing method ${ }^{[16]}$.

Rebhasabharwal's study focuses on what factors contribute to women using or not using contraceptive measures to control her fertility. The literature shows that contraceptive use varies by the age of the women, woman's educational level \& her partner's educational levels are also predictors ${ }^{[17]}$.

Weeam S Hammoudeh, NiveenME.Abu-Rmeleh studied that women's education, employment, access to and knowledge of contraception have been highlighted as important predictors of fertility and contraception by demographers. Couple attitudes towards family planning, family desire and women's ability to make decisions regarding the use of family planning were important predictors of family planning use. Men's attitudes played a bigger role in determining actual child bearing behavior than that of their wives ${ }^{[18]}$.

G Santhya studied that contextual and structural factors (high levels of illiteracy, poor access to sources of knowledge, poverty, and gender and non gender based disparities) are responsible. The direction, the emphasis and strategies followed hitherto in the family welfare programme have largely contributed to the limited success of the programme. There is an increasing recognition of various barriers to promoting contraceptive choice and meeting contraceptive needs in the country ${ }^{[19]}$.

Farooqahmed, Sohail Chand studied that fourteen religious, demographic and socio-economic factors of categorical nature like husband education, wife education, husband's monthly income, occupation of husband, household size, husband-wife discussion, number of marriage, offering of prayers, political view, and religiously decisions were taken to understand acceptance of family planning ${ }^{[20]}$.

Visaria, Leela (1999) studied that variation in fertility are generally examined in terms of socioeconomic factors such as education, income, caste, place of residence. These factors can affect fertility only through intermediate variables such as proportion of females married, prevalence of contraceptive use, incidence of induced abortion and the fertility inhibiting effect on breast feeding ${ }^{21]}$.

Currently married women, who are not using a contraceptive method fall into 2 categories with respect to their contraceptive experience-those who used contraception in the past(Ever users) and those who never used contraception(Never users).

Studies have revealed that $59.6 \%$ of women admit the most common problem of hesitation to ask for a contraceptive method even from her husband and from the health worker. Non availability of the facility in the village was given as a reason by $43.2 \%$, fear of side effects by $36.6 \%$, customs, disbelief or social pressure by $22 \%$ and $0.6 \%$ gave economic problems as a reason ${ }^{[22]}$. 
A study undertaken in hard core pockets of urban slums of Pune revealed the reasons for nonacceptance of family planning methods, were desire to have male/female child (17.7\%), heavy bleeding after $\mathrm{Cu}$ $\mathrm{T}$ insertion (13.9\%) and refusal by male partner (19.3\%) ${ }^{[23]}$.

Family pressure was cited as a reason for non-acceptance by one fifth of the respondents by Kartikeyan $\mathrm{S}^{[24]}$. Acceptance of permanent methods of sterilization is determined by number of living children and more so by male children. It was noted that $37 \%$ of sterilized women had three living children and $30 \%$ had 4 living children. Average numbers of children reported by Saha per tubectomised children was $4^{[25]}$. Low acceptance of temporary methods which was $7 \%$ seen predominantly among the higher secondary educated women, which is in contrary to the studies which reveal that the use of temporary methods are more popular among women with at least middle school education than among those with less education. Urban women are more likely than rural women to have discussed family planning. The proportion of women reporting such discussions rises with women, husband's education and the standard of living index ${ }^{[26]}$.

In no surveyed country do married women report their desired family size at or below Replacement level fertility ${ }^{[27]}$. The dominant method in Tamil nadu is sterilization, which women tend to accept only after achieving their desired family size ${ }^{[28]}$. In a similar study, in their analysis found that both husband's and wife's education is indicative of their contraceptive practices and any education overall contributes contraceptive use $^{[29]}$

.In East Delhi in 2001, 59.8\% of the eligible couples were currently using a contraceptive Method $^{75}$. This shows that there is not just interstate but also intrastate difference in the use of family planning methods. Studies reveal that among those who had underwent sterilization, tubectomy was more common $(74.6 \%)$ than vasectomy $(1.3 \%)^{[30]}$.

In a study done in East Delhi, of the 59.8\% eligible couples who were using a contraceptive method, condom was the most common (33.4\%) method of contraception followed by other spacing methods $(32.3 \%)$ and tubectomy $(27.3 \%)^{[31]}$.In the study conducted in Kolkata, the major reason for unmet need was opposition from husband, family and community leaders $(32 \%)^{[32]}$.

\section{Conclusion}

$110(36.66 \%)$ had two number of living children in the study and 172(57.36\%) of women had desire for two children. Those who preferred son, 46(63.88\%) gave reason as son can be a future source of income. In the study group, among the 300 respondents $176(58.6 \%)$ were current users. 54(30.68\%) were in the age group of 25-29years.Among the current users $126(71.59 \%)$ had undergone Tubectomy and none were found who had adopted Vasectomy as a contraceptive method in the study population.100(56.81\%) were belonging to Hindu community in the study. $81(46.02 \%)$ of current users had Secondary level of education and $180(60 \%)$ were belonging to Class III socio-economic status and $82(46.6 \%)$ of current users had two children. 156(88.7\%) women used contraception to limit their family size and $122(69.4 \%)$ used contraception after birth of first child. Reasons for not using contraception for majority 70(56.5\%) was desire for more Children, 25(20.2\%) as need not felt, $13(10.5 \%)$ as against religion and misconception about contraception and $1(0.80 \%)$ as mother in law opposition, lack of information and fear of side effects.129(92.2\%) had negative opinion towards male sterilization and majority $74(57.4 \%)$ gave reason for negative opinion as weakness will develop in males following male sterilization.280 (93.4\%) of husbands of study population had agreed for contraception and $20(6.6 \%)$ had disagreed.284 (94.4\%) of husbands wanted same number of children as wife and 15(5\%) wanted more number of children than wife.

$>$ Family planning programme should concentrate on young married women and mostly the spacing methods which are more applicable to the young couples, while the permanent method should be concentrated on the older age group women.

> IEC components of family planning programmes should include among target audiences, older women and husband who may be obstacles to the adoption of contraception by the woman in need.

$>$ In order to be effective, programmes must include counseling and education to help women disentangle fact from fiction regarding health and side effects of methods.

$>$ Women who do not seek contraceptive services because they believe they are not at risk of getting pregnant require information through outreach efforts outside of a clinical setting.

$>$ Health personnel need to educate and motivate couples to use reversible methods since delaying the births can also help to reduce the fertility and thus help in controlling the population.

$>$ Efforts to promote societal receptivity to contraceptive use can help women overcome the cultural and social barriers to achieve their desired family size.

$>$ Social changes outside the domain of the family planning programme, such as policies to enhance female economic autonomy, may be equally important in the long run. In order to address the role of son preference, two major societal changes are needed: first, the educational and economic 
empowerment of women and second, the provision of a social security net which prevents parents from being solely dependent on their male offspring in advanced age.

$>$ Primarily the community and the families' attitude should change towards women's education, by way of women's empowerment, interactive club etc. This can improve their standard of living in the community, thereby increasing the age at marriage for better acceptance and compliance of contraceptive use.

$>$ Inter-spouse communication should be improved by means of men's involvement and access to reproductive health information and services, which will enable them to take responsible reproductive decisions. This would also improve their attitude towards acceptance of spacing methods and vasectomy.

\section{Acknowledgment}

I thank all the teaching and non teaching staff members and faculty of Dr.B.R.Ambedkar Medical College and Family members for the support.

\section{References}

[1]. Park, k., Demography and family planning. Text book of preventive and social medicine, 21stEdition: Jabalpur, M/s BanarsidasBhanot Publishers; 2011, Page no 443,445,447,454.

[2]. Malcolm Potts; the unmet need for Family Planning. Scientific American, January 2000, 88-93.

[3]. Lori Ashford. Unmet Need for Family Planning: Recent trends and Their Implications for Programs.Population Reference Bureauwww.prb.org/pdf/unmetneed Fam Plan-Eng.pdf.

[4]. Health Benefits of Family Planning and Population Division of Family Health, World Health Organization, 1994.

[5]. Anthony, O. Igwegbe, Joseph, O. Ugboaja and Emmanuel, N. Monago.Prevalence and determinants of unmet need for family planning in Nnuewi, South-east Nigeria. International Journal of Medicine and Medical Sciences. Vol. 1(8), pp. 325-329, August, 2009.

[6]. Coombs, L. C. \& Chang, M. (1981). Do Husbands and Wives agree? Fertility attitudes and later behavior. Population and Environment, 4(2):109-127.

[7]. Visariaet al, 1999. From family planning to reproductive health: Challenges facing India. International Family Planning Perspectives, Volume 25: Supplement.

[8]. Contraceptive Use Rises, But Unmet Needs Remain.Population Centre www.unfpa.org/intercentre/hopes/contrac.htm.

[9]. The Concept of Unmet Needs, its Extent and Trends.Available from http://populationcommission.nic.in/unmet-contraception.htm

[10]. Bhattacharya S.K, Ram R, Goswami D.N, Gupta U.D, Bhattacharya K, Ray S.Study of Unmet Need for Family Planning among Women of Reproductive Age Group Attending Immunization Clinic in a Medical College of Kolkata. Indian Journal of Community Medicine, April-June 2006 Vol 31, No-2, 73-75.

[11]. Andurkar S.P, Yadav V.B, Dalvi S.D. Study of Unmet need for family planning among married women of reproductive age in urban health central field practice area of Govt Medical College, Aurangabad. Indian Journal of Public Health, Jan-March 2006, Vol -50, No-1, 45-46.

[12]. Rajaretnam T, Deshpande R.V. Factors inhibiting the use of reversible contraceptive methods in rural South India.Studies in Family Planning, 1994 www.cehat.org/publications/rhr4.html.

[13]. Mohanan P, Kamath A, Sajjan B.S. Fertility Pattern and Family Planning Practices in a Rural Area in DakshinaKannada.Indian Journal of Community Medicine, Jan-March 2003, Vol 28, No-1.

[14]. Bulatao, Rodolfo A. and (1983).“'Overview of Determinants of fertility in Developing Countries and Fertility in Bangladesh". Socia Biology. Vol. 44 Nos. 3-4.Fall-Winter: 179-197.

[15]. P. S. Nair, Griffith Feeney, Vinod K. Mishra, and Robert D. Retherford.FactorsAffecting Source Of Family Planning Services in India. NFHS subject Report No. 12(1999).

[16]. Baveja R et.,al.Evaluating contraceptive choice through the method mix approach.ICMR Task force Study. Contraception 2000 Feb;61(2):113-119.

[17]. Rebhasabharwal. Factors associated with contraception in India. Center for Population Dynamics.Arizona State University.Population Association of America 2009.

[18]. Weeam S Hammoudeh, Nirveen ME, Abu-Rmeileh. Factors associated with the use offamily planning among Palestinian women. Paper presented at the IUSSP XXVI International Conference, 27 September 2009-2 Oct 2009, Marrakech, Morocco.

[19]. G Santhya. Changing family Planning scenario in India: An overview of recentevidence.Regional Working Papers, South East Asia.Population Council, New Delhi, India 2003, No. 17.

[20]. Farooq Ahmed, Sohail Chand. Log Linear Models for Religious and Social Factors affecting the practice of Family Planning Methods in Lahore, Pakistan.Pak.J.stat. Oper.Res.Vol.ii No. 12006 pp (35-44).

[21]. Visaria. Pravin. 1999. Proximate Determinants of Fertility in India: An Exploration of NFHS Data. Economic and Political Weekly 34(42\&43): 3033-3040.

[22]. Jainsetal.Attitude of Rural Women towards Contraception and its use. Indian Journal Maternal and Child Health 1999;10(1):18.

[23]. Vaidya V G,Suhasrabndhe B G,Jogi J A,Mitkar R P.Profile of sterilized women in urban slums and evaluation of motivational strategies. Indian J of Public Health Jan-Mar 2003 47(1):31-33.

[24]. Kartikeyan. S., Chaturvedi. R.M. Family Planning: Views of female Non acceptors in Rural India, ICMR Project, Solapur.

[25]. Saha S P.Trends in socio demographic characteristics of tubectomy acceptors in rural areas of West Bengal. Indian Journal of Public Health 1981 3:102.

[26]. NFHS 2(National Family Health Survey), 1998-1999, Mumbai International Institute of Population Sciences, 2000.NFHS2(Karnataka), 1999-2000, www.nfhsindia.com

[27]. Zlidar, V.M.,et.,al.New survey findings: The Reproductive Revolution Continues.PopulationReports. Series M, No.17, Sept-Oct 2003:3, 7,16,20,22,23,24,25.25. Kirk D and PilletB.Fertility Trends and Differentials in Sub Saharan Africa in the 1980's and 1990's.Studies in Family Planning 1998, 29(1):1-22.

[28]. National Family Health Survey-3, Fact Sheet Karnataka (Provisional Data), 2005-2006, www.nfhsindia.org. 
[29]. P.Jayarani Reddy. Differential Contraceptive use among the slum and non slum dwellers.A Study of Hyderabad city. Health and Population-Perspectives and Issues 7(2):115-128, 1984

[30]. Manish Gupta, MeenalZambare. Knowledge, Attitude and Practice of women regarding family planning in Maharashtra.Indian J.Maternal and Child Health 1999:10(3\&4):48.

[31]. Kansal A, Chandra R, Kandpal S D, Negi K.S. Epidemiological Correlates of Contraceptive Prevalence in Rural Population of Dehradun District. Indian Journal of Community Medicine, April-June 2005, Vol 30, No-2, 60-62. http://populationcommission.nic.in/unmet-contraception.htm.

[32]. Rama Ram, Ghosh M.N, Bhattacharya S, Haldar A, Chatterjee C, NaskarN.Study of Unmet Need for Family Planning Among Married Women of Reproductive Age Attending Immunization Clinic in a Medical College of Calcutta.Indian Journal of Community Medicine, Jan-Mar 2000, Vol 25, No-1. 